\title{
La necesidad de publicar y el nacimiento de las revistas médicas depredadoras
}

\author{
Alejandra Castañón-González ${ }^{1}$, Jaime Javier Cantú-Pompa², Alejandro Miranda-Hernández ${ }^{3}$ \\ y Julio César López-Valdés ${ }^{4}$

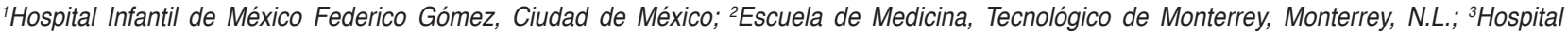 \\ Pediátrico privado, Ciudad de México; ${ }^{4}$ Médico Cirujano, Facultad de Medicina de Tampico Dr. Alberto Romo Caballero, Universidad Autónoma de \\ Tamaulipas, Tampico, Tamps. México
}

\section{Sr. Editor:}

Antes que nada, quisiéramos agradecer el tiempo otorgado para leer este escrito; sin embargo, el motivo de la presente es permitirnos el atrevimiento de plantearle nuestra inquietud respecto a un problema que ha ido en aumento, y consideramos necesita mención: el nacimiento de las revistas depredadoras (predatory journals), cuya expansión ha sido de características exponenciales durante los últimos años $y$, además, han definido un área de la literatura médica que intenta engañar a autores y lectores. Aunque alrededor del mundo han causado controversia, tanto en la literatura médica mexicana como en la hispanoparlante no existen recomendaciones ni registros en relación a ella. Dicho esto, los autores consideran menester generar un antecedente que ponga en alerta a aquellos lectores que aún sean ajenos al tema en cuestión.

Si bien la alta competencia académica ha orillado a las nuevas generaciones a ampliar su ambición no solo dentro del campo clínico, sino a incurrir en el área de la investigación médica, la aparición del fenómeno Internet ha originado una transformación radical de las publicaciones académicas gracias a la aparición de versiones electrónicas paralelas de mayor difusión; empero, como hacen constar Shen y Björk ${ }^{1}$, dicha particularidad dio paso a un efecto secundario: la nueva perspectiva para el replanteamiento radical por parte de las editoriales como proveedores de servicios para los autores (p. ej., revisión por expertos en el tema, edición e inclusive la misma publicación), y no como medios de difusión de conocimiento. Es así como, en este modelo, los autores pagan a los editores por el servicio de «libre acceso» (open access) para una distribución universal2,3. No obstante, lejos de representar un cambio favorable, ha ocasionado que la integridad de la evidencia producida se vea comprometida, ya que han surgido publicaciones poco éticas, denominas revistas depredadoras ${ }^{1-4}$, cuya principal intención es generar ganancias a partir del cobro por procesar el manuscrito. Todo esto, aunado a que hoy en día el escenario profesional es un entorno rápidamente cambiante, en donde la investigación es un requisito esencial para la elegibilidad en promociones laborales, ha ocasionado que la necesidad de publicar se vea enormemente acrecentada; en pocas palabras, las revistas depredadoras explotan una debilidad fundamental en la investigación académica: la necesidad de un investigador de publicar artículos para avanzar en su carrera, y los autores que anhelan buenos resultados inmediatos caen en la trampa. Además, los escritores que informan en estas periódicas se enfrentan al reto de perder su esfuerzo, ya que los sitios web de esta clase de revistas pueden desaparecer en cualquier momento.

Comúnmente, estas «pseudo-revistas» científicas se promocionan de manera masiva mediante el uso de nombres atractivos o similares a los de
Gac Med Mex. 2017;153:516-517

Contents available at PubMed www.gacetamedicademexico.com 
publicaciones académicas legítimas, y se acompañan de métricas infladas o inexistentes, a través de invitaciones personalizadas por correo electrónico, en las que prometen una revisión expedita con un periodo de publicación corto. Sin embargo, este tipo de editoriales tienen poco interés por la calidad científica o la rectitud del trabajo. Pese a que parece fácil detectar este tipo de literatura, reconocerla en la práctica es más complicado; por tal motivo, en años recientes, el académico profesor Jeffrey Beall ${ }^{3}$, con el fin de alertar a la comunidad científica sobre este peligro, así como disminuir la corrupción del sistema de acceso abierto, dio a conocer una lista (Beall's list) ${ }^{5}$ en la cual se incluyen aquellas revistas y grupos editoriales con alta sospecha de prácticas fraudulentas y académicamente desacreditables. Cabe mencionar que la lista ha sido actualizada con el paso del tiempo y, en algunos casos, no solo las editoriales de acceso abierto cuyas prácticas coinciden con características pertenecientes a «literatura depredadora" se han añadido al directorio. Por esto, alrededor del mundo, la «lista Beall» ha sido considerada como un parteaguas para el cribado inicial en la selección de un grupo editorial (o inclusive revista) como depositario de los resultados obtenidos tras la realización de un trabajo de investigación. Sin embargo, paralelamente, estas revistas han ocasionado el nacimiento de "autores depredadores" 6 que suelen publicar artículos falsos o investigaciones poco detalladas y de baja reproducibilidad, con el fin de «engordar» sus historiales académicos ${ }^{6,7}$. A su vez, dicha merma académica origina una clase de fenómeno caótico al ser utilizada por otros científicos para su investigación, llegando a establecer las bases de sus averiguaciones en publicaciones inciertas.

Por lo tanto, los autores consideran que existe el apuro de generar conciencia y advertir a los lectores sobre la existencia y la proliferación de estas prácticas sin ética y desmerecedoras a la medicina ${ }^{6-8}$. De igual forma, se recomienda que los académicos lean las reseñas disponibles con respecto al tema, así como las evaluaciones y las descripciones en diversos artículos.

\section{Bibliografía}

1. Shen C, Björk BC. 'Predatory' open access: a longitudinal study of article volumes and market characteristics. BMC Medicine. 2015;13:230.

2. Masten YB, Ashcraft AS. The dark side of dissemination: traditional and open access versus predatory journals. Nurs Educ Perspect. 2016;37:275-7.

3. Beall J. Predatory journals threaten the quality of published medical research. J Orthop Sport Phys Ther. 2017;47:3-5.

4. Clemons M, De Costa e Silva M, Joy AA, et al. Predatory invitations from journals: more than just a nuisance? Oncologist. 2017:22:236-40.

5. Beall J. Beall's list of predatory publishers. Scholarly Open Acces. (Consultado el 20 de enero de 2017.) Disponible en: https://scholarlyoa. com/2016/01/05/bealls-list-ofpredatory-publishers-2016

6. Narimani M, Dadkhah M. Predatory journals and perished articles; a letter to editor. Emergency. 2017;5:e49.

7. Beall J. Best practices for scholarly authors in the age of predatory journals. Ann R Coll Surg Engl. 2016;98:77-9.

8. Beall J. Dangerous predatory publishers threaten medical research. Korean Med Sci. 2016;31:1511-3. 